\title{
A Clinical Audit to Assess the Adherence of the Code Blue Team to Advanced Cardiac Life Support Protocol and its Effect on the Patient Outcome in a Tertiary Care Hospital in Kochi, Kerala
}

\author{
Indhu Aynipully Jayasingh, Athish Peter Margos R, Shoba Philip \\ Departments of Critical Care Medicine and Anaesthesiology and Critical Care, Lourdes Hospital, Kochi, Kerala, India
}

Abstract

Introduction: Cardiopulmonary resuscitation is a sequence of techniques that combines chest compression with artificial ventilation to manually maintain the circulation to preserve intact brain function. The aim is to maintain circulation and breathing in a person who is in cardiac arrest until emergency aid arrives. Effective teamwork by Code Blue team raises chances of a successful outcome. The advanced cardiac life support (ACLS) guidelines were developed by the American Heart Association using the comprehensive review of resuscitation literature performed by the International Liaison Committee on Resuscitation. Aim: To assess adherence of Code Blue team to ACLS protocol, to assess outcome of resuscitation, and to compare outcome between those where ACLS guidelines were followed and those not followed. Patients and Methods: A clinical audit was done between 2014 and 2015 at Lourdes Hospital, Kochi, on inpatients aged between 30 and 80 years, with witnessed cardiac arrests/respiratory arrest. Pregnant and unwilling patients were excluded. Results: The common arrest rhythm was pulseless electrical activity, followed by asystole. ACLS protocol was followed in $58.7 \%$. The most common deviation was usage of inappropriate drugs. Return of spontaneous circulation (ROSC) was attained in $53.3 \%$, of which $28.5 \%$ were discharged $(P<0.05)$, which suggests a significant association between the adherence to ACLS protocol and ROSC. Conclusion: Although Code Blue team is ACLS trained, deviations occurred in nearly half of the resuscitations, which need to be reduced. Outcome was better in those resuscitations where the ACLS protocol was followed.

Keywords: Advanced cardiac life support protocol, cardiopulmonary resuscitation, cardiorespiratory arrest, Code Blue team

\section{INTRODUCTION}

The field of resuscitation has taken two centuries to evolve. Mouth-to-mouth ventilation for drowning victims was recommended by The Paris Academy of Science in 1740. The first documented chest compressions on humans were performed by Dr. Friedrich Maass in 1891. The American Heart Association (AHA) formally endorsed cardiopulmonary resuscitation (CPR) in 1963, and by 1966, the standardized CPR guidelines were adopted for instruction to lay-rescuers. The guidelines have been continually evolving based on scientific evidence and expert consensus. The most recent advanced cardiac life support (ACLS) guidelines was published in 2010 by the AHA and updated in 2015. ${ }^{[1]}$ The ACLS training programs have been increasingly concentrating on uniformity of imparting education and in its application. The guidelines have been simplified, and every step described

\begin{tabular}{|l|l|}
\hline \multicolumn{2}{|c|}{ Access this article online } \\
\hline Quick Response Code: & Website: \\
& www.ijrconline.org \\
& \\
\end{tabular}

is crucial in determining outcome. This study was aimed at evaluating how much of this education actually gets translated into practice and its impact on outcome.

\section{Patients and Methods}

This clinical audit was done by reviewing the Code Blue records from 2014 to 2015 at Lourdes Hospital, Pachalam, Kochi. It was a retrospective study. The records of witnessed cardiac arrests among in-hospital patients aged 30-80 years

Address for correspondence: Dr. Indhu AJ, 42/642, Azhepparamb, Kannachan Thodu Junction, Kochi- 682018, Kerala, India E-mail:drindhuaj@gmail.com

This is an open access article distributed under the terms of the Creative Commons Attribution-NonCommercial-ShareAlike 3.0 License, which allows others to remix, tweak, and build upon the work non-commercially, as long as the author is credited and the new creations are licensed under the identical terms.

For reprints contact: reprints@medknow.com

How to cite this article: Jayasingh IA, Margos RA, Philip S. A clinical audit to assess the adherence of the Code Blue team to advanced cardiac life support protocol and its effect on the patient outcome in a tertiary care hospital in Kochi, Kerala. Indian J Respir Care 2018;7:46-9. 
Jayasingh, et al.: Adherence of the Code Blue team to ACLS protocol

were scrutinized. Records of patients in whom the relatives were not willing for continuation of treatment after attainment for successful return of spontaneous circulation (ROSC) and those patients who were pregnant at the time of death were excluded.

\section{Study design}

The records were screened to see whether ACLS guidelines were followed, how many had ROSC, and of those who achieved ROSC, how many survived to discharge [Figure 1]. The data were compared to look for any differences in outcome among those patients, in whom the ACLS guidelines (2010) were followed and in those in whom they were not.

Data were collected from Code Blue flowcharts that were maintained in the hospital during the period 2014-2015. The chart includes demographic data such as age and gender, whether the resuscitation team looked for response, breathing and pulse, initial rhythm, whether defibrillation used, method of ventilation, whether ROSC was achieved, and whether he/she survived to discharge.

Data were entered into Microsoft Excel and then drafted into SPSS (IBM, USA) software. Frequency tables were created using the SPSS software version 24 . Chi-square test was used to assess if any significant relationship existed between the resuscitations, in which ACLS protocol was followed and in those in which it was not followed.

\section{RESULTS}

A total of 150 patient files were studied. The demographic data are given in Table 1.

The most common arrest rhythm identified was pulseless electrical activity, followed by asystole. Ventricular tachycardia (VT) and ventricular fibrillation (VF) constituted only 3.3 and $4 \%$, respectively [Table 2]. Seventy-four percent of them did not require defibrillation as they did not have any shockable rhythm. Twenty-five percent were resuscitated in $<20 \mathrm{~min}$. Out of $88(58.7 \%)$ patients in whom ACLS protocol was strictly followed, 59 had ROSC. The remaining $41.3 \%$ had some deviation from the ACLS algorithms [Table 3]. The most common deviation was seen to

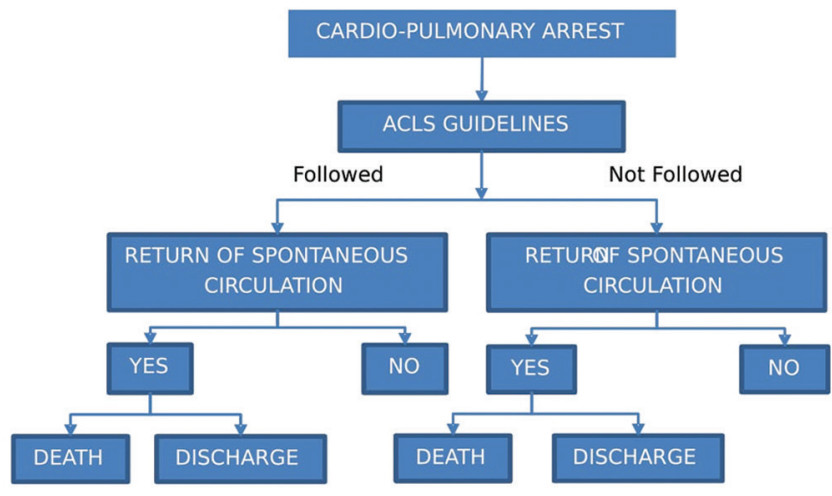

Figure 1: Study design

\begin{tabular}{lc}
\hline $\begin{array}{l}\text { Table 1: Age and gender distribution of the study } \\
\text { population }\end{array}$ & Frequency \\
\hline & \\
\hline Age in years & 9 \\
$31-40$ & 22 \\
$41-50$ & 31 \\
$51-60$ & 46 \\
$61-70$ & 42 \\
$71-80$ & \\
Gender & 104 \\
Male & 46 \\
Female & \\
\hline
\end{tabular}

Table 2: Details of resuscitation

\begin{tabular}{|c|c|}
\hline Parameter & Number of cases \\
\hline \multicolumn{2}{|l|}{ Initial response } \\
\hline Response activated & 146 \\
\hline Palpated for pulse & 40 \\
\hline Chest compression & 141 \\
\hline \multicolumn{2}{|l|}{ Breathing pattern } \\
\hline Apnoeic & 119 \\
\hline Agonal & 31 \\
\hline \multicolumn{2}{|l|}{ Ventilation } \\
\hline Bag and mask only & 54 \\
\hline Bag and mask with endotracheal intubation & 96 \\
\hline \multicolumn{2}{|l|}{ First identified arrest rhythm } \\
\hline Pulseless electrical activity & 106 \\
\hline Asystole & 41 \\
\hline $\begin{array}{l}\text { Ventricular fibrillation/ventricular } \\
\text { tachycardia }\end{array}$ & 11 \\
\hline \multicolumn{2}{|l|}{ Need for defibrillation during the resuscitation } \\
\hline No defibrillation & 111 \\
\hline Defibrillation $\times 1$ & 11 \\
\hline Defibrillation $\times 2$ & 13 \\
\hline$>2$ defibrillations & 15 \\
\hline \multicolumn{2}{|l|}{ Total duration of resuscitation } \\
\hline$<5 \min$ & 13 \\
\hline $6-10 \min$ & 25 \\
\hline $11-15 \mathrm{~min}$ & 12 \\
\hline $16-20 \mathrm{~min}$ & 13 \\
\hline $21-25 \mathrm{~min}$ & 14 \\
\hline $26-30 \mathrm{~min}$ & 21 \\
\hline$>30 \mathrm{~min}$ & 52 \\
\hline \multicolumn{2}{|l|}{ Final outcome } \\
\hline Expired & 127 \\
\hline Discharged & 23 \\
\hline
\end{tabular}

Table 3: Comparison of return of spontaneous circulation with adherence to algorithm

\begin{tabular}{lccc}
\hline & ROSC & No ROSC & Total \\
\hline Algorithm followed & 59 & 29 & 88 \\
Algorithm not followed & 21 & 41 & 62 \\
Total & 80 & 70 & 150 \\
\hline Chi-square test $P<0.0001$. ROSC: Return of spontaneous circulation
\end{tabular}


be administration of inappropriate drugs, followed by usage of drugs less than indicated $(11.3 \%)$ or too many (8\%) [Table 4 ]. Inappropriate shock was administered in 1.3\%. Although 80 out of $150(53.3 \%)$ patients had ROSC, $28.5 \%$ of them were discharged uneventfully [Table 5].

\section{Discussion}

Respiratory arrest is the cessation of breathing. When a patient goes into respiratory arrest, if their respiration is supported promptly, cardiac arrest due to the consequent hypoxia can be averted. However, if oxygenation is not adequate, they may suffer brain damage or cardiac arrest within minutes. ${ }^{[2]}$ Cardiac arrest is often due to electrical malfunction resulting in VF or VT resulting in loss of pulse. ${ }^{[3]}$ Since blood flow ceases to all organs including vital organs, respiration also ceases and eventually leads to death. CPR is an emergency procedure that combines chest compression and artificial ventilation to manually ensure blood flow and oxygenation, thus preserving organ function. At the same time, efforts are made to restore spontaneous circulation and breathing in a person who is in cardiac arrest. ${ }^{[4]}$

Table 4: Parameters not adhered to in the advanced cardiac life support 2010 resuscitation algorithms

\begin{tabular}{lc}
\hline & Frequency \\
\hline Inappropriate drugs & 31 \\
Too less drugs & 17 \\
Too many drugs & 13 \\
Inappropriate shock & 1 \\
\hline
\end{tabular}

Table 5: Survival to discharge in those patients who had return of spontaneous circulation

\begin{tabular}{lc}
\hline & $\boldsymbol{n}(\%)$ \\
\hline Expired & $57(71.5)$ \\
Discharged & $23(28.5)$ \\
\hline
\end{tabular}

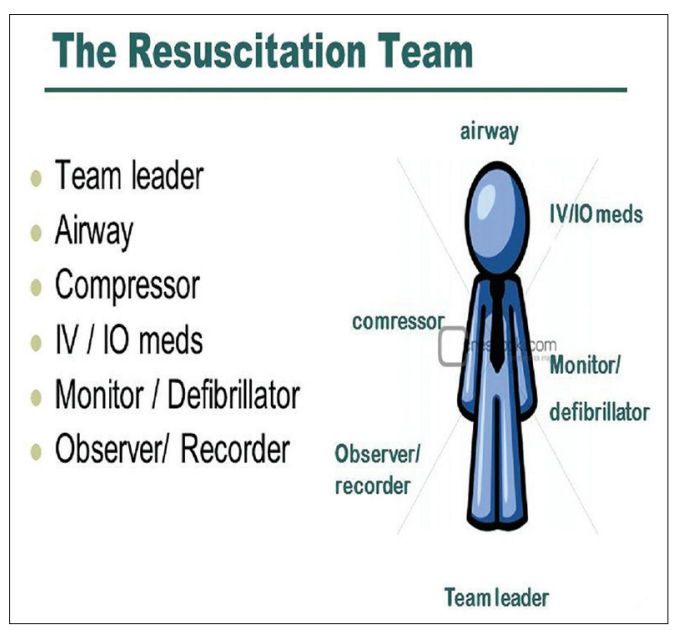

Figure 2: Resuscitation team
CPR, especially if performed appropriately and in the first few minutes of cardiac arrest, can double or triple a person's chance of survival. ${ }^{[5]}$ The 2010 AHA Guidelines for CPR and Emergency Cardiovascular Care (ECC) was developed by the 2010 International Consensus on ECC and CPR Science with Treatment Recommendations Conference. AHA Guidelines Latest Update for CPR and ECC was published in 2015. ${ }^{[6]}$

CPR should be initiated immediately on an unconscious and pulseless patient. Steps of Basic CPR include assessing unconsciousness, calling for help, confirmation of the absence of breathing and pulse, followed by the initiation of cardiac compressions and ventilation. As soon as the automated external defibrillator is available, the presence of shockable rhythms (VF and pulseless VT) must be looked for so that they can be shocked and hope to attain ROSC. In addition, CPR should be resumed immediately after a defibrillatory shock until a pulsatile state is established. ${ }^{[7]}$

\section{Code Blue}

It is an emergency situation announced in a hospital or institution, announced when a patient is in cardiopulmonary arrest and a designated team of responders (called the "code blue team") [Figure 2] rush to the specific location and begin immediate resuscitative efforts. ${ }^{[8]}$ The team is trained to follow resuscitation guidelines, and the tasks are divided among team members. They must maintain their training and work collectively in an organized manner for the best possible outcome. ${ }^{[9]}$

Survival rates and neurologic outcomes are poor for patients with cardiac arrests. Early CPR, early defibrillation, recommended drugs, and appropriate implementation of postcardiac arrest care lead to improved survival and neurologic outcomes. Studies have shown that, in cardiac arrest without CPR delivery, survival falls by $10 \%-15 \%$ for each minute of delay.

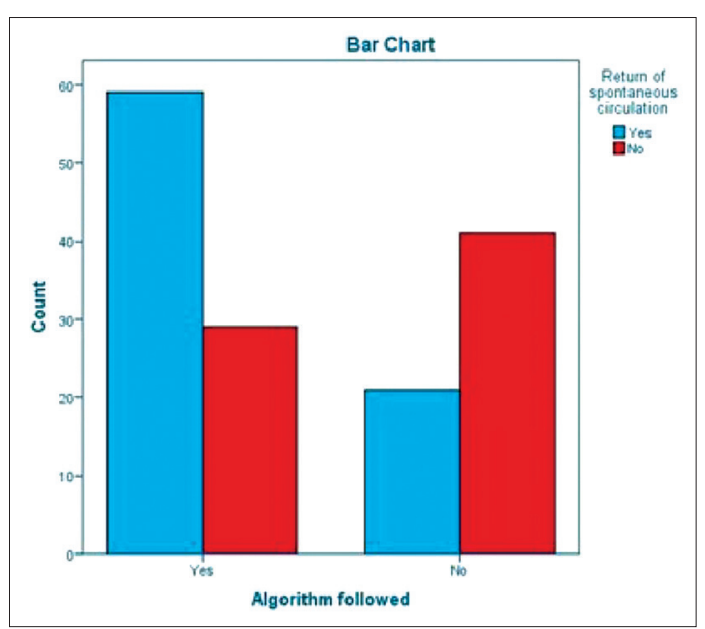

Figure 3: Comparison of return of spontaneous circulation in those patients where the algorithm was followed to those where the algorithm was not followed 
The AHA-sponsored National Registry of CPR conducts prospective, multisite, observational study of in-hospital resuscitation. About 14,720 cardiac arrests between the period of January 1, 2000, and June 30, 2002, occurred in adults at the 207 participating hospitals. Overall, $44 \%$ of adult in-hospital cardiac arrest victims had an ROSC; $17 \%$ survived to hospital discharge. ${ }^{[10]}$

Similar results were seen by McEvoy et al.$^{[1-14]}$ The immediate success of resuscitation efforts for all patients was better with relation to other studies, but as the aim of the study was to assess adherence and outcome in those patients, the study of other factors contributing to the success of CPR was beyond scope.

The incidence of VT and VF was low. One possible explanation could be that arrhythmias occur less commonly in in-hospital arrests, which was only included in this study. Arrhythmias may be higher in out-of-hospital arrests. That may be the reason that our study had lower incidence of arrhythmias compared with other studies.

The most common error is the use of inappropriate drugs. Three possible reasons may explain this. First, the lack of knowledge of the appropriate drugs during CPR as advised in the ACLS protocol. Considering that all members of our Code Blue team are ACLS trained, this is less likely. Second, lack of belief in the ACLS protocols may cause this. Third, inappropriate drugs may be used as a measure of desperation. This decreases the chances of survival for the patient. It must be regularly reinforced to the Code Blue team that just following the algorithm is more likely to result in ROSC than unwarranted drugs.

The survival-to-discharge ratio is still low. This is similar to other studies. This shows that the potential of a patient to get discharged also depends on other factors such as underlying disease process and comorbidities which eventually decide the final outcome. However, proper ACLS followed resuscitation raises immediate survival and gives a chance to reverse the disease process [Tables 3 and 5].

There was a significant increase in ROSC with ACLS protocol, followed by resuscitations in comparison with those resuscitations where ROSC was not followed [Figure 3]. This has also been shown in other studies consistently. It emphasizes the need to regularly reinforce ACLS protocols among the Code Blue members and strict monitoring.

\section{Conclusion}

Regular re-enforcement ACLS protocols among the Code Blue members are essential. It must be communicated to the Code Blue team that following the ACLS algorithm is more likely to result in ROSC. Strict monitoring of the performance of the Code Blue team is needed.

\section{Financial support and sponsorship}

Nil.

\section{Conflicts of interest}

There are no conflicts of interest.

\section{REFERENCES}

1. Available from: http://www.uptodate.com/contents/ advanced-cardiac-life-support-acls-in-adults. [Last accessed on 2017 Nov 20].

2. Available from: https://www.acls.com/free-resources/ respiratory-arrest-airway-management/managing-respiratory-arrest. [Last accessed on 2017 Oct 25].

3. Available from: http://www.heart.org/HEARTORG/Conditions/More/ CardiacArrest/About-Cardiac-Arrest_UCM_307905_Article.jsp\#. WD7YCrJ97IU. [Last accessed on 2017 Oct 25].

4. Cardiopulmonary Resuscitation; 2017. Available from: https://www. en.wikipedia.org/wiki/Cardiopulmonary_resuscitation. [Last accessed on 2017 Jan 13].

5. Available from: http://www.cpr.heart.org/AHAECC/CPRAndECC/ AboutCPRFirstAid/CPRFacts AndStats/UCM_475748 CPR-Facts-and-Stats.jsp. [Last accessed on 2017 Dec 29].

6. Available from: http://www.cpr.heart.org/AHAECC/CPRAndECC/ AboutCPRFirstAid/HistoryofCPR/UCM_475751_History-of-CPR.jsp.

7. Available from: http://www.emedicine.medscape.com/ article/1344081-overview. [Last accessed on 2017 Dec 29].

8. Available from: http://www.medicinenet.com/script/main/art. asp?articlekey=59953. [Last accessed on 2017 Jan 13].

9. Sinz E, Navarro K, Soderberg E. Advanced Cardiovascular Life Support Provider Manual. American Heart Association; 2011. p. 60-1.

10. Peberdy M, Kaye W, Ornato J, Larkin G, Nadkarni V, Mancini M, et al. Cardiopulmonary resuscitation of adults in the hospital: A report of 14720 cardiac arrests from the National Registry of Cardiopulmonary Resuscitation. Resuscitation 2003;58:297-308.

11. McEvoy MD, Field LC, Moore HE, Smalley JC, Nietert PJ, Scarbrough SH, et al. The effect of adherence to ACLS protocols on survival of event in the setting of in-hospital cardiac arrest. Resuscitation 2014;85:82-7.

12. Moretti MA, Cesar LA, Nusbacher A, Kern KB, Timerman S, Ramires JA, et al. Advanced cardiac life support training improves long-term survival from in-hospital cardiac arrest. Resuscitation 2007;72:458-65.

13. Ornato JP, Peberdy MA, Reid RD, Feeser VR, Dhindsa HS; NRCPR Investigators. Impact of resuscitation system errors on survival from in-hospital cardiac arrest. Resuscitation 2012;83:63-9.

14. Motamedi M, Piryaie M, Rafati H, Saghafi A, Jalali A, Madani S, et al. Survival after in-hospital cardiopulmonary resuscitation in a major referral center. Saudi J Anaesth 2010;4:68. 